\title{
Simulation Study of Ignition Characteristics of Impinging Sprays in Constant Volume Chamber
}

\author{
Sanaur Rehman ${ }^{1}$, Shah Shahood Alam² \\ ${ }^{1,2}$ Combustion and Pollution Control Laboratory, Department of Mechanical Engineering, ZHCET, \\ AMU, Aligarh, India \\ ${ }^{1}$ Email: sanaur.rehman@zhcet.ac.in \\ 2Email: sshahood2004@yahoo.co.in
}

\begin{abstract}
The present study involves the simulation of a constant volume, non-premixed, hot surface spray combustion of diesel fuel for a given set of injection pressure, compressed air pressure (cylinder air pressure) and hot surface temperature (hot plate temperature) and their effects on ignition delay period. Fuel injection pressure was varied from 100 bar - 300 bar in steps of 100 bar, cylinder air pressure in the range of 20 bar to 40 bar (in steps of 10 bar) and hot surface temperature from $623 \mathrm{~K}$ to $723 \mathrm{~K}(50 \mathrm{~K}$ steps). The problem was solved using 2D axisymmetric geometry. A structured mesh of about 1.24 lac nodal points was created and tested for grid independency. For solving flow behavior, a pressure solver was used with a turbulence model of $\mathrm{k}-\varepsilon$ with enhanced wall functions. While a volumetric eddy dissipation model was used to solve combustion phenomena. Ignition delay period was calculated with the help of static temperature versus time plot. It is found that keeping any two operating parameters constant, third operating parameter is inversely proportional to ignition delay period. The results of the present simulation study are in a fairly good agreement with the experimental studies at same operating conditions.
\end{abstract}

Keywords: Hot surface ignition, simulation, diesel fuel, constant volume chamber

\section{Introduction}

Diesel engine combustion is a very complex phenomenon. Various processes affect the diesel engine combustion such as atomization and evaporation of the liquid fuel, mixing of the fuel vapor with surrounding gas, self-ignition of the fuel-air mixture, turbulence induced by air and fuel jet, interaction of the fuel jet with cylinder walls, heat transfer between the fuel and the surrounding gases and between combustion gases and the cylinder walls, etc. [1]. The homogeneous air-fuel mixing in time is largely influenced by the combustion chamber geometry and fuel injection characteristics [2].

Modern high speed DI diesel engines have high power density and high cylinder air pressures (up to 180 bar) for achieving high efficiency $[1,3]$. Due to high power density and cylinder air pressures, the piston surface temperature gets increased and its role in ignition of spray becomes important. Recent trends towards smaller engine sizes with high pressure common-rail injection systems have increased spray/piston interactions and cause extensive fuel spray impingement on 
piston bowl walls [4,5]. Impingement of the fuel jet on the walls occurs in almost all of the small high speed diesel engines [1]. It is found that relatively few studies have been undertaken for analyzing ignition characteristics of impinging diesel sprays combustion in a constant volume combustion chamber (CVCC) [5-11]. Out of these, majority are experimental and only a few are numerical. Therefore, present study has tried to bridge the gap between the two by performing simulations using Ansys to evaluate the performance of a CVCC utilizing a diesel spray impinging on hot surface (plate).

\section{Problem Formulation}

The aim of the present study is to compare the simulation results with the published experimental results [7] with respect to ignition delay period for the same CVCC dimensions and operating conditions. The typical dimensions of CVCC are given in table 1. Properties of diesel fuel $\left(\mathrm{C}_{10} \mathrm{H}_{22}\right)$ is given in table 2. The present work has utilized Ansys Fluent for carrying out simulations.

The simplified geometry consists of a fuel inlet, heat plate. Top, end and bottom faces are set to walls (heat flux and symmetric respectively) and is shown in Fig. 2.1.

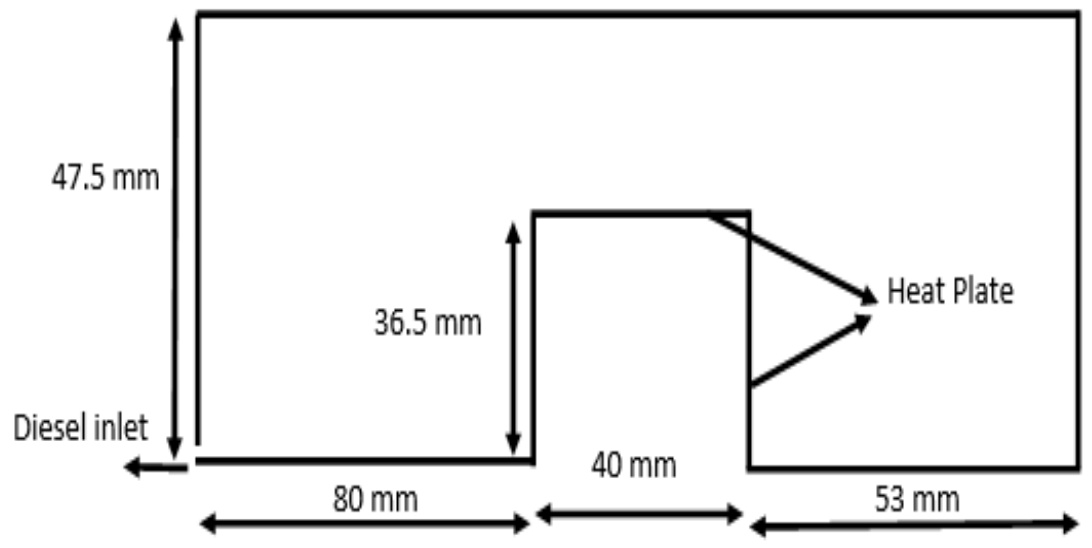

Figure 2.1: Block diagram of an axisymmetric heat plate combustion

Table 1 Geometric details of the combustion chamber

\begin{tabular}{|c|c|}
\hline Length of the combustor & $173 \mathrm{~mm}$ \\
\hline Height of the combustor & $47.5 \mathrm{~mm}$ \\
\hline Diameter of fuel inlet nozzle & $0.15 \mathrm{~mm}$ \\
\hline Height of heat plate & $36.5 \mathrm{~mm}$ \\
\hline Length of heat plate & $40 \mathrm{~mm}$ \\
\hline Fuel inlet to heat plate distance & $80 \mathrm{~mm}$ \\
\hline
\end{tabular}


Table 2 Diesel fuel $\left(\mathrm{C}_{10} \mathrm{H}_{22}\right)$ Properties

\begin{tabular}{|c|c|}
\hline Critical Temperature & $725.9 \mathrm{~K}$ \\
\hline Critical pressure & $2089 \mathrm{kPa}$ \\
\hline Latent heat & $254 \mathrm{~kJ} / \mathrm{kg}$ \\
\hline Boiling point & $536.4 \mathrm{~K}$ \\
\hline Density & $846 \mathrm{~kg} / \mathrm{m}^{3}$ \\
\hline
\end{tabular}

\subsection{Grid generation and its specification}

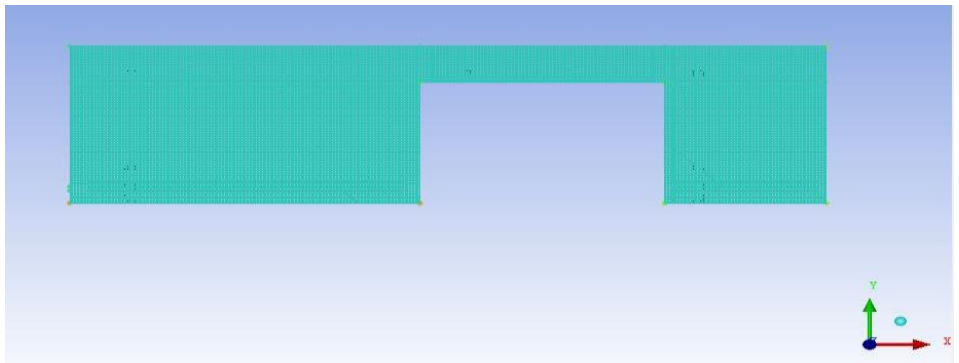

Figure 2.2: Meshed Geometry

The grid independence test was performed with four different two dimensional grids whose specifications are given in Table 3. Simulation done on these meshed geometry with different grid number. Third meshed geometry with grid number $126 \mathrm{~K}$ showing less variation in results when comparing with validating paper.

Table 3 Mesh specifications for grid independence test

\begin{tabular}{|c|c|c|c|}
\hline Mesh & Cells & Nodes & Grid expansion ratio \\
\hline Mesh 1 & 25674 & 26202 & 1.10 \\
\hline Mesh 2 & 54553 & 55320 & 1.10 \\
\hline Mesh 3 & $\mathbf{1 2 5 1 7 4}$ & $\mathbf{1 2 6 3 3 2}$ & $\mathbf{1 . 1 0}$ \\
\hline Mesh 4 & 234456 & 235848 & 1.10 \\
\hline
\end{tabular}

\subsection{Boundary conditions}

In the present simulation study, the hot surface temperature was varied from $623 \mathrm{~K}$ to $723 \mathrm{~K}$ in steps of $50 \mathrm{~K}$. The cylinder air pressures were $20 \mathrm{bar}, 30 \mathrm{bar}$ and $40 \mathrm{bar}$ and fuel injection pressures chosen were 100 bar, 200 bar and 300 bar. Fuel $\mathrm{C}_{10} \mathrm{H}_{22}$ mass fraction was $0.0116 \mathrm{~kg} / \mathrm{s}$. 


\subsection{Governing equations}

The equations of continuity, momentum, energy, mixture fraction, turbulence and combustion including those related to chemical kinetics have to be solved simultaneously to model the flow field. The k- $\varepsilon$ model is one of the most common turbulence models. It is a two equation model which means that two extra transport equations is included to represent the turbulent properties of the flow. These two equations are solved together in order to solve for turbulence. The k- $\varepsilon$ model gives good prediction in the free stream and it is less sensitive to values chosen for free stream turbulence properties, it means that this model can model free stream flow to a sufficient degree. Modelling the combustion is one of the most challenging problems in the field of computational fluid dynamics (CFD). Two models are used for combustion in this study: Eddy Dissipation Model (EDM) and Finite Rate and Eddy Dissipation model (FRED). These models are used to solve the interaction between turbulence and combustion. In FRED model, the eddy dissipation combustion model (EDM) which derives from the eddy dissipation concept is extended to simulate combustion within large eddy simulations (LES). Reaction rates are assumed to be controlled by the turbulence, so expensive Arrhenius chemical kinetic calculations can be avoided. The model is computationally cheap but for realistic results, only one or two step combustion model should be used.

\section{Results and Discussion}

Ignition delay or delay period in diesel engine is defined as the time interval between the start of fuel injection and start of combustion (appearance of flame) $[1,5,6]$. It is found that fuel injection pressure controls ignition delay or/delay period, duration of combustion and rate of heat release in diesel engines [1] due to better mixing of air-fuel mixture. It also exerts influence on other related parameters like spray tip penetration, mixture formation, flame pattern and turbulence and emissions. Shorter ignition delay and duration of combustion are favored in diesel combustion for better performance [6,7].

In the present work, simulations were run at different fuel injection pressures, hot plate temperatures and cylinder air pressures, keeping any two variables as constant for a particular simulation. A pressure based transient solver was used with a time step size of 1e-4 s. The governing equations of axisymmetric turbulent flow with realizable $\mathrm{k}-\varepsilon$ turbulence model and enhanced wall treatment, together with total energy and species transport for non-premixed combustion were solved. The mesh contained about 0.3 million cells with least non-dimensional first element height of 5e-4. A probability density function (PDF) comprising of 20 intermediate reaction species with temperature ranging from $300 \mathrm{~K}-2200 \mathrm{~K}$ with a varying mixture fraction of 0.2-1.8 was developed and solved as a part of Shvab-Zeldovich Energy Equation.

A Discrete Phase Model (DPM) was used to model the ignition phenomenon with diesel fuel being injected in form of evaporative liquid droplets at different injection pressures ranging from 100300 bar after the combustion chamber is filled with compressed air. Change of pressure/temperature at various perpendicular axes across the combustion chamber were plotted with respect to flow time. Ignition delay was considered as the first aggressively high peak in the temperature versus time plot. 


\subsection{Effect of fuel injection pressure}

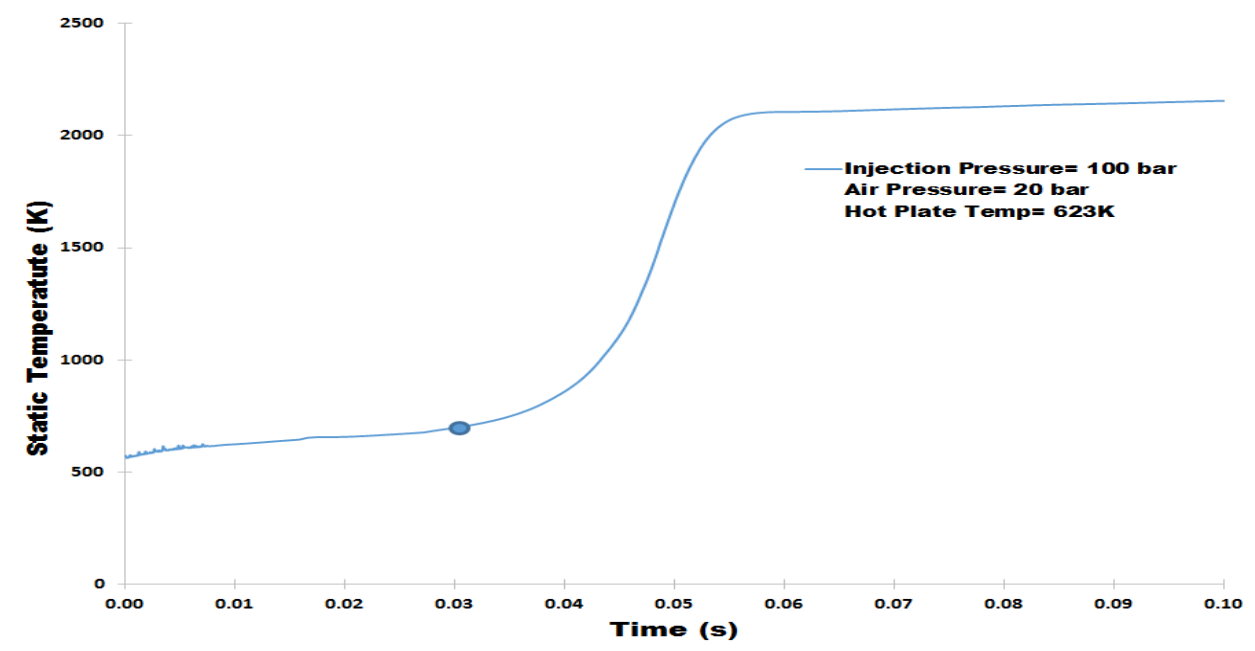

(A)

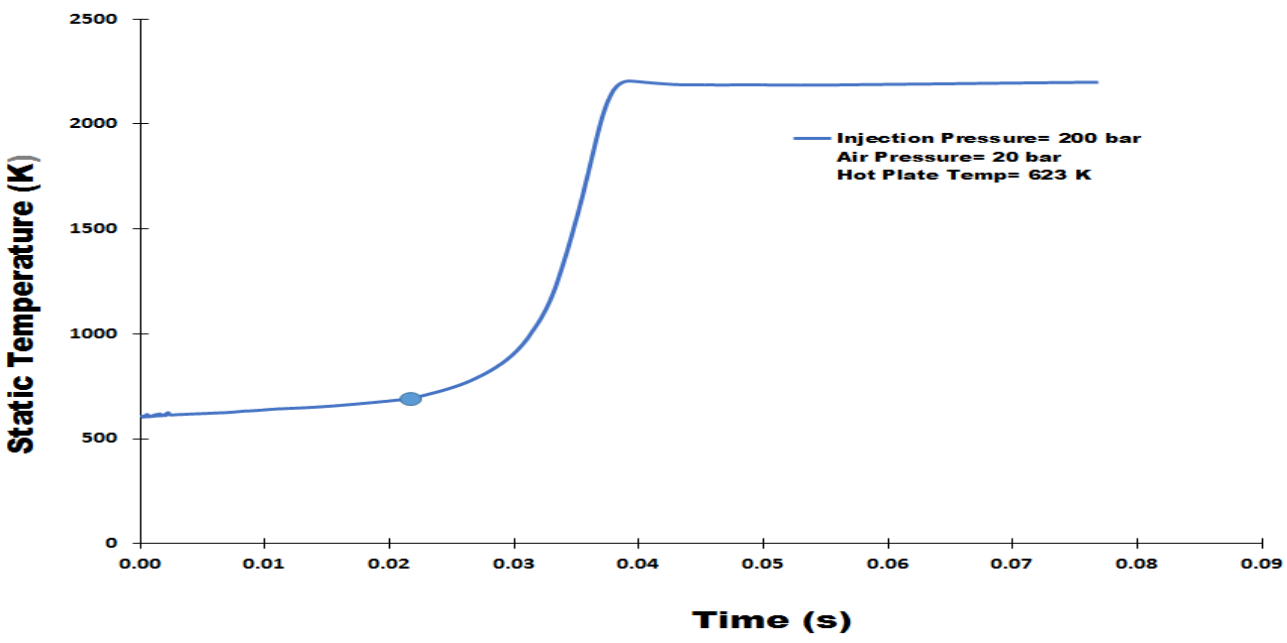

(B)

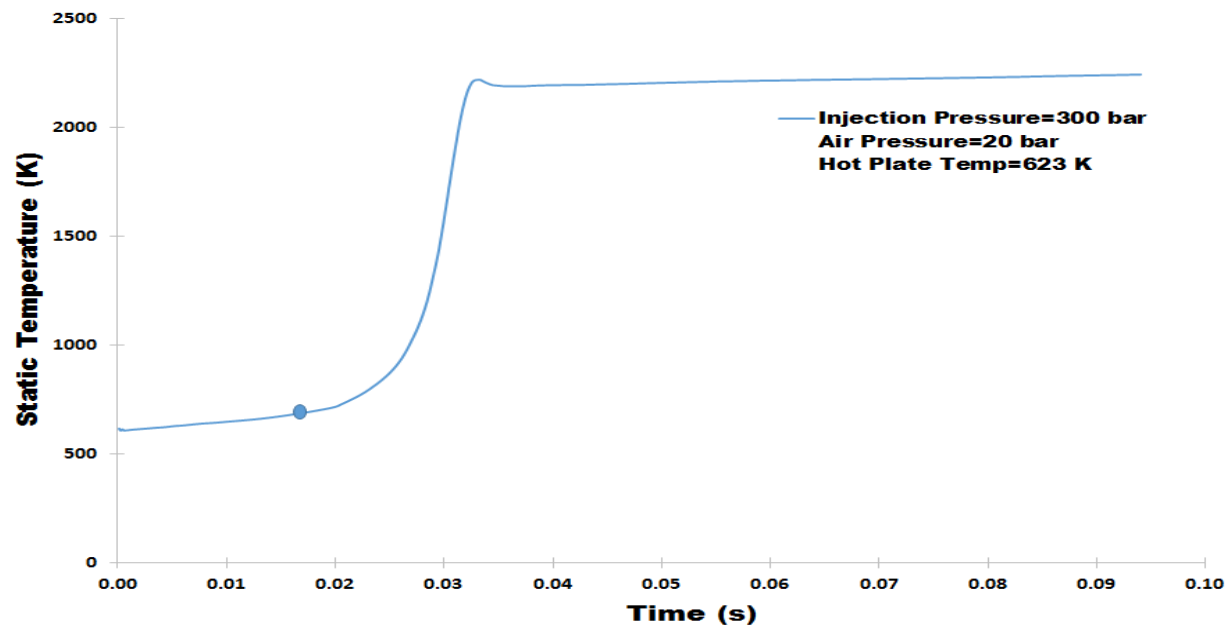

(C)

Figure 3.1 Static temperature vs time (A) IP of 100 bar, (B) IP of 200 bar and (C) IP of 300 bar. 


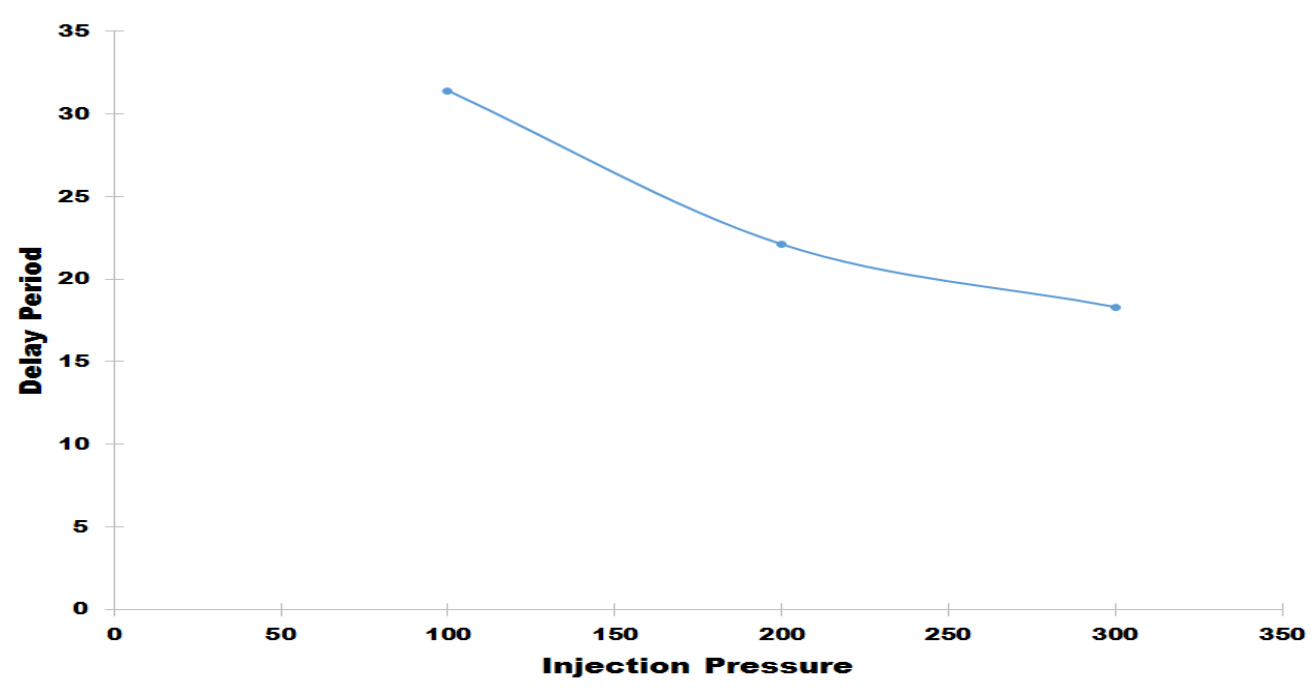

Figure 3.2: Delay period (ms) versus injection pressure

Figure 3.1 shows the static temperature variation with time at various operating conditions. In all graphs of figure 3.1, ignition delay period (in $\mathrm{ms}$ ) as the time difference between start of injection (at time equal to zero ms) and point of first aggressively high peak in the temperature (indicated by blue solid circle on temperature curve). It is noted in figure 3.1 that ignition delay period decreases with increase in injection pressure from 100 bar to 300 bar. Figure 3.2 suggests that delay period decreases with an increase in injection pressure from 100 bar to 300 bar, at fixed values of hot plate temperature (623K) and cylinder air pressure (20 bar). The reduction in delay period may be attributed to better atomization of liquid fuel droplets (due to enhanced turbulence) and breakup of the fuel jet due to reduced surface tension, thus improving evaporation and leading to better mixing of air and fuel mixture thereby reducing the physical delay and resulting in a more complete combustion process [12]. The present result for CVCC also agrees qualitatively with those of engine research [1].

\subsection{Effect of hot plate temperature}

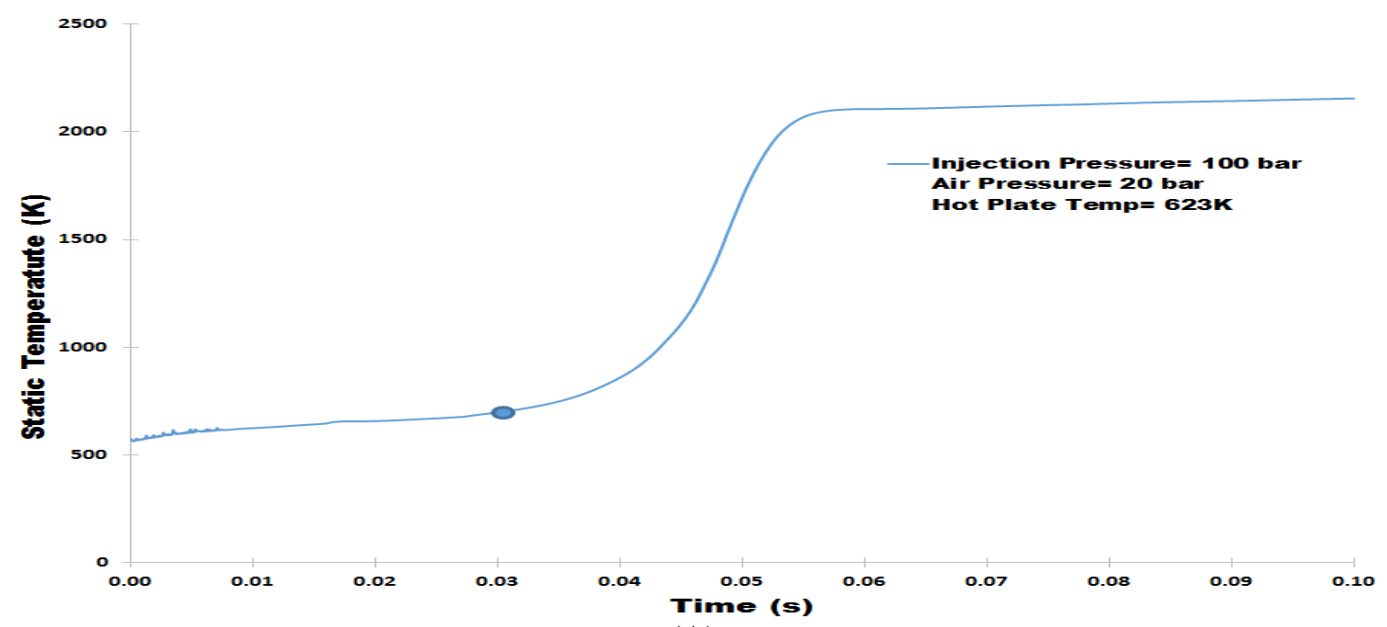

(A) 


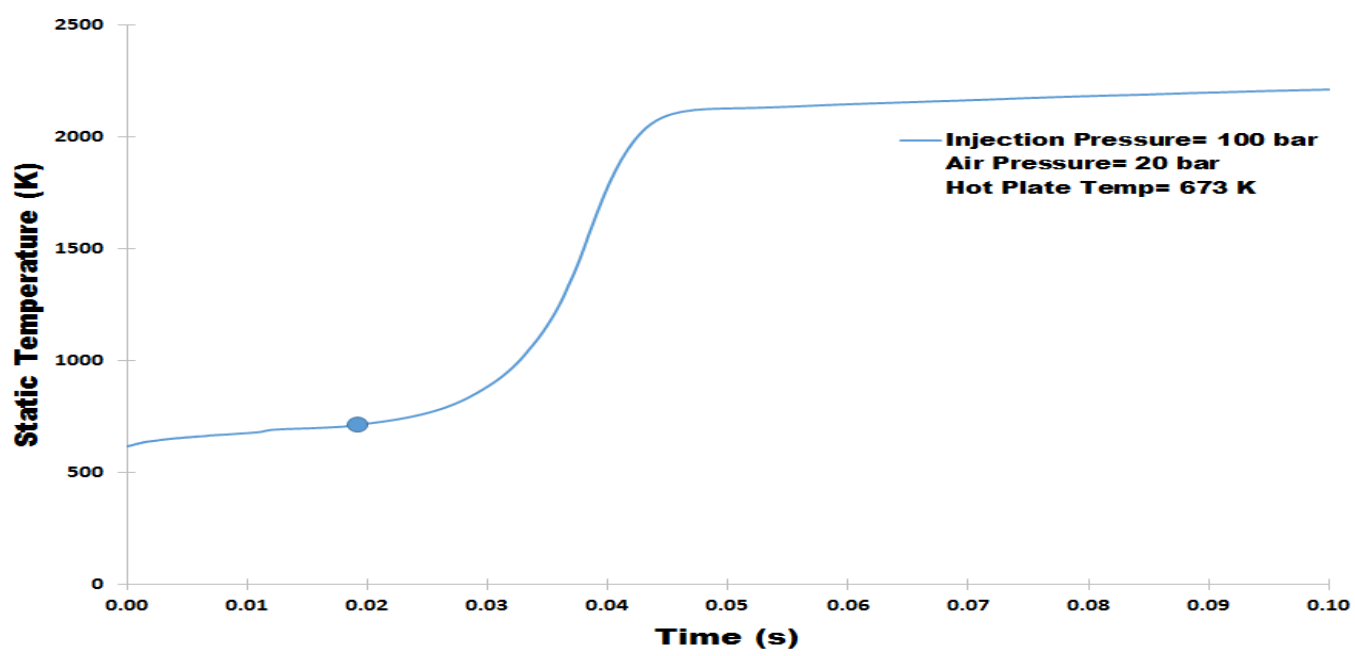

(B)

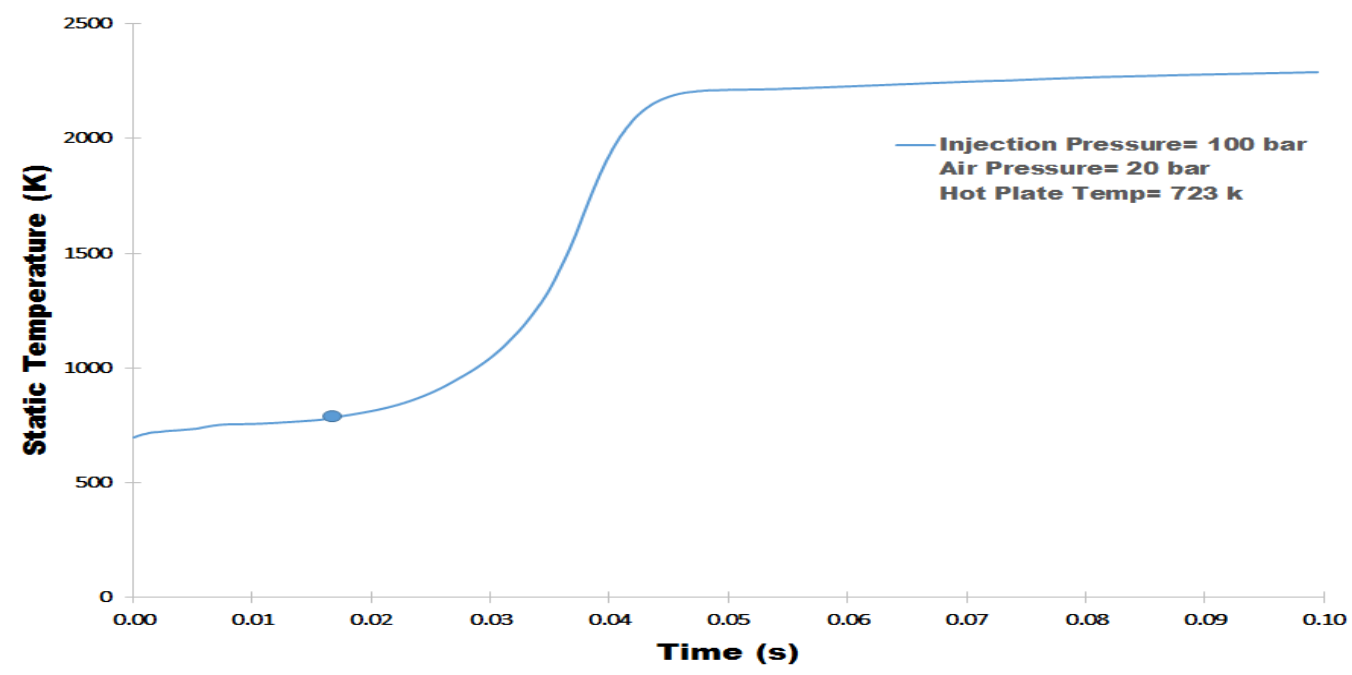

(C)

Figure 3.3Static temperature vs time (A) HST of $623 \mathrm{~K}$, (B) HST of $673 \mathrm{~K}$ and (C) HST of $723 \mathrm{~K}$.

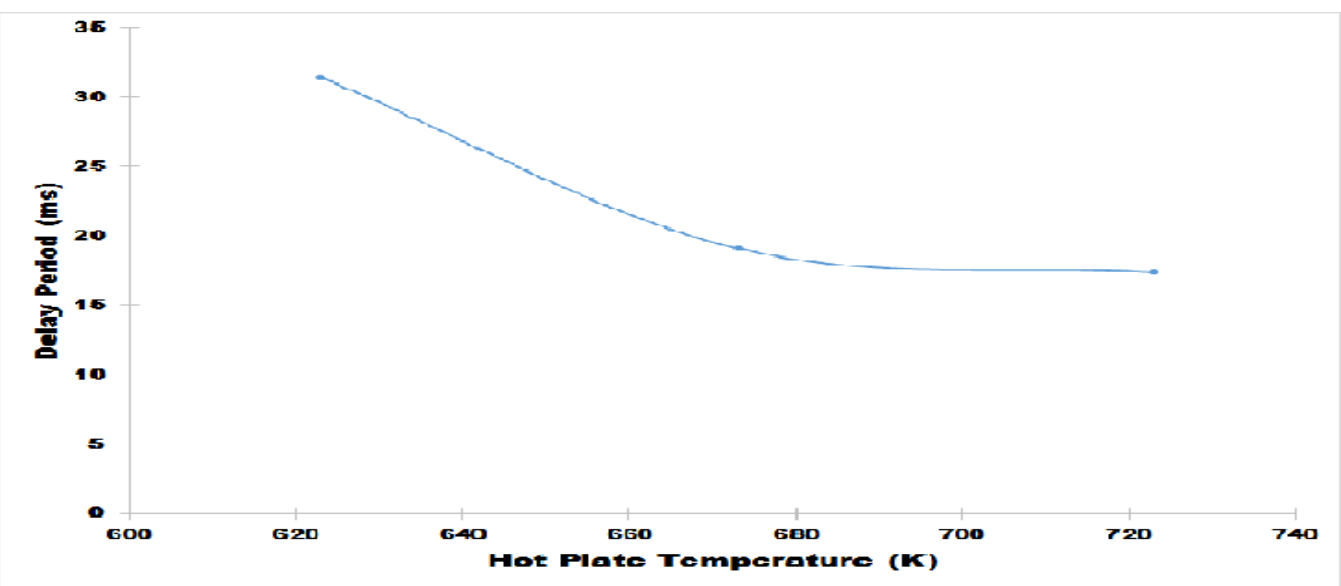

Figure 3.4 Delay period versus hot plate temperature 
Graphs in Fig. 3.3 indicates variation of static temperature with time at different hot surface temperature keeping other operating conditions constant. With the help of graphs in Fig. 3.3 we obtained values of ignition delay period at different hot surface temperatures. It is found from all graphs of Fig. 3.3 that with increase in hot surface temperature delay period decreases.

Use of hot surface as ignition source has emerged as preferred combustion actuating mechanism for realizing the benefits of direct injection because of the combustion robustness of a continuous ignition source which can initiate combustion of diesel fuel spray at or near TDC. Fig. 3.4 depicts that delay period decreases with an increase in hot plate temperature for fixed fuel injection pressure (100 bar) and cylinder air pressure (20 The reason for reduced delay period with high surface temperature may be due to the fast fuel evaporation of the impinging fuel sprays (liquid droplets) on hot surface leading to the short physical delay period $[5,6]$. This result for CVCC is in general agreement with other experimental studies related to diesel engine combustion [1,7].

\subsection{Effect of cylinder air pressure}

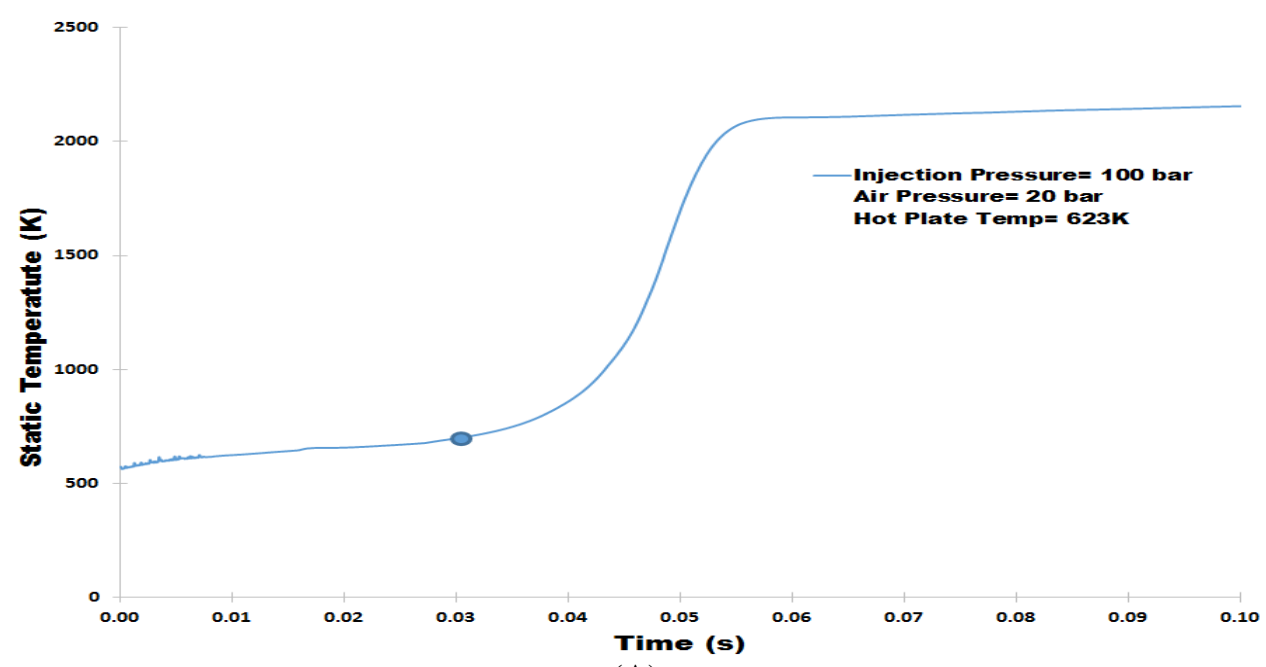

(A)

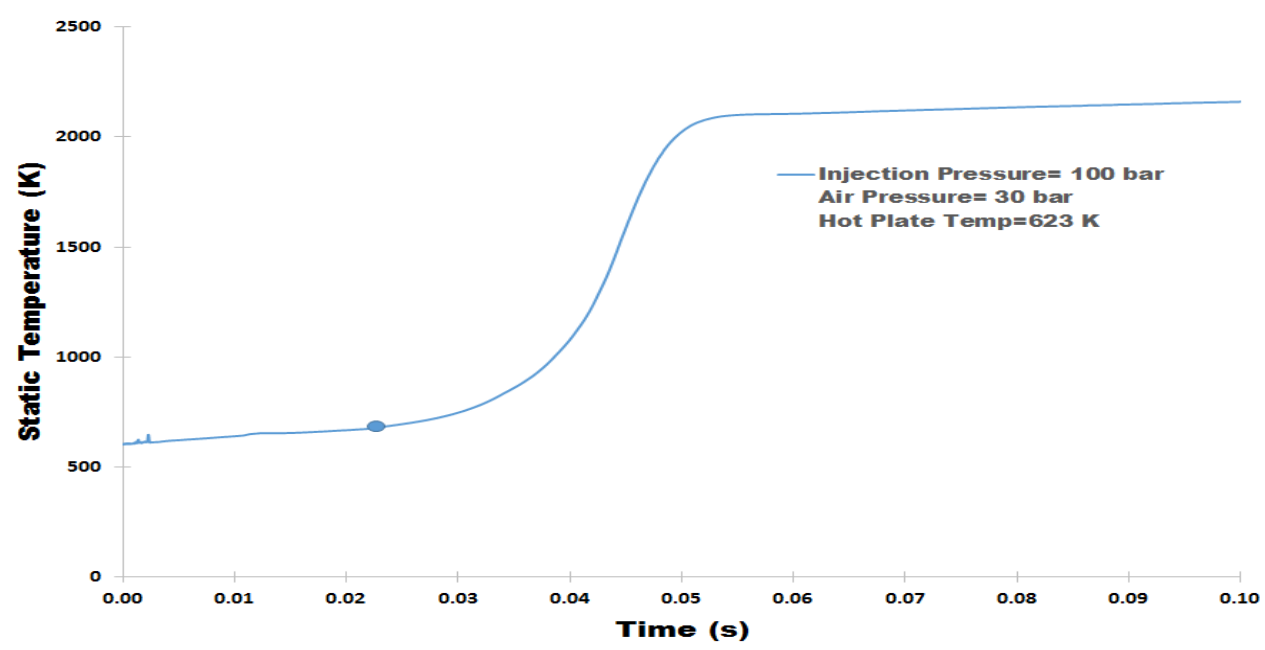

(B) 


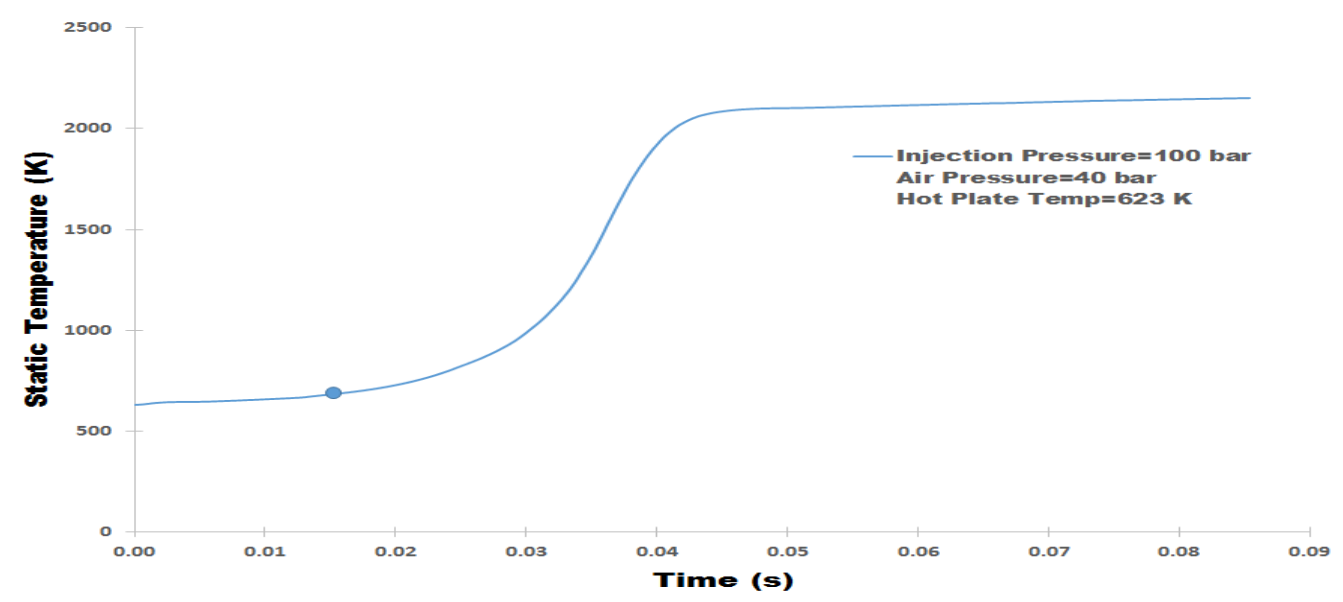

(C)

Figure 3.5 Static temperature vs time (A) CP of 20 bar, (B) CP of 30 bar and (C) CP of 40 bar.

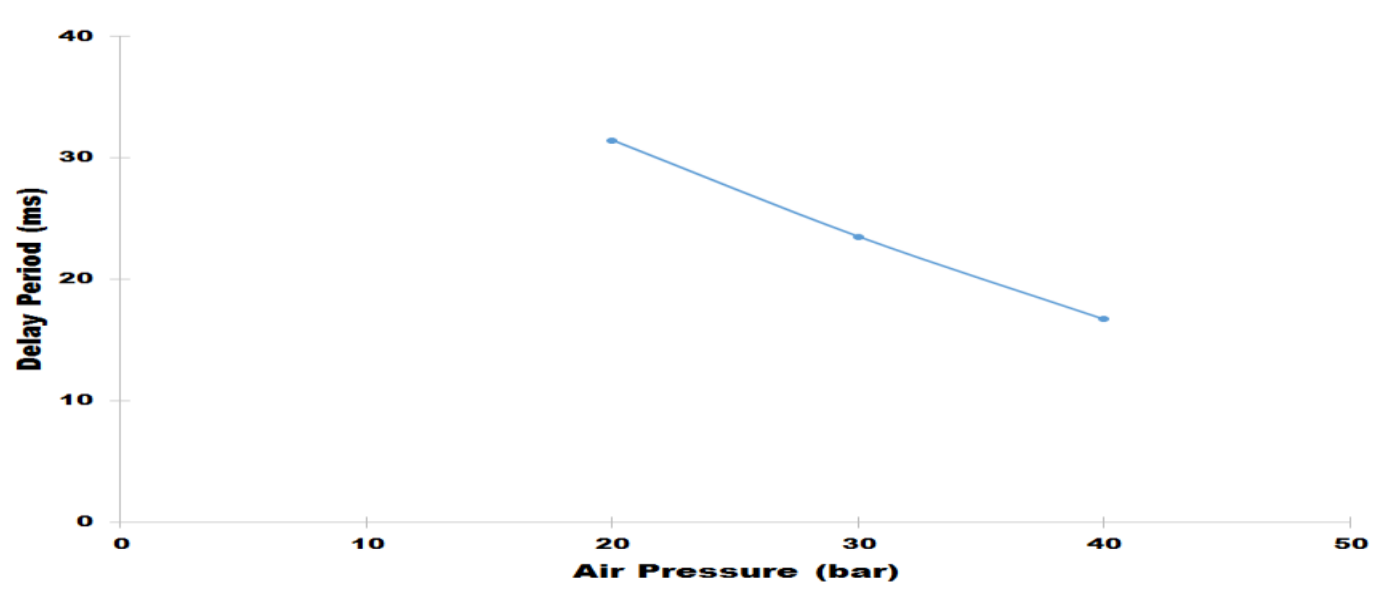

Figure 3.6 Variation of delay period with air pressure

From all graphs in Fig. 3.5, ignition delay period is noted at different cylinder air pressures keeping other operating parameters constant. Figure 3.6 shows that for constant fuel injection pressure and hot plate temperature of 100 bar and $623 \mathrm{~K}$ respectively, delay period decreases with an increase in cylinder air pressure from 20 bar to 40 bar. One possible reason for this behavior is that as the air pressure increases, air density increases leading to a decrease in fuel auto-ignition temperature and subsequently a lesser delay period [14]. This trend is also verified by other experimental studies $[1,7]$. 


\section{Validation studies}

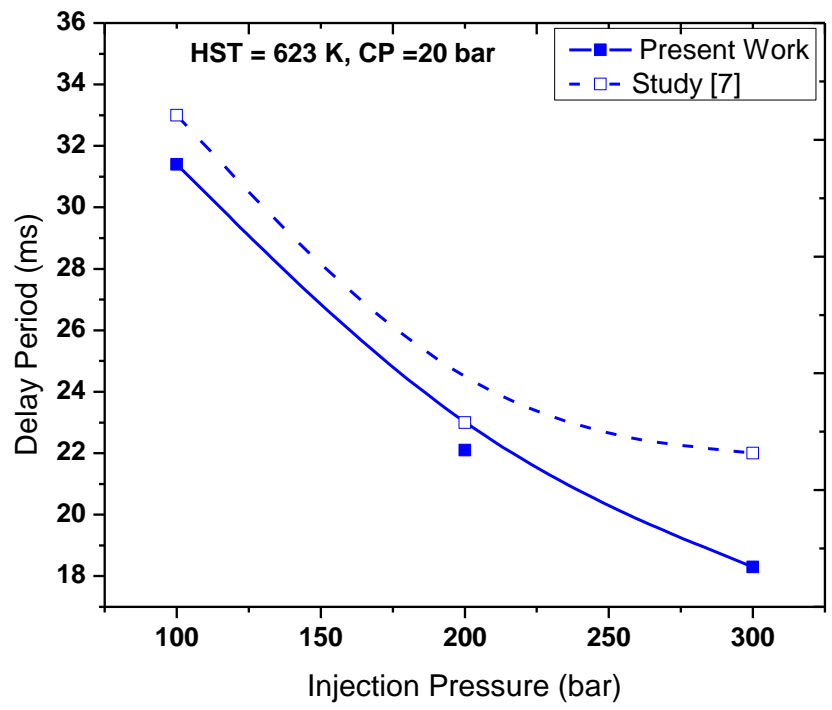

Figure 4.1 Delay period against injection pressure

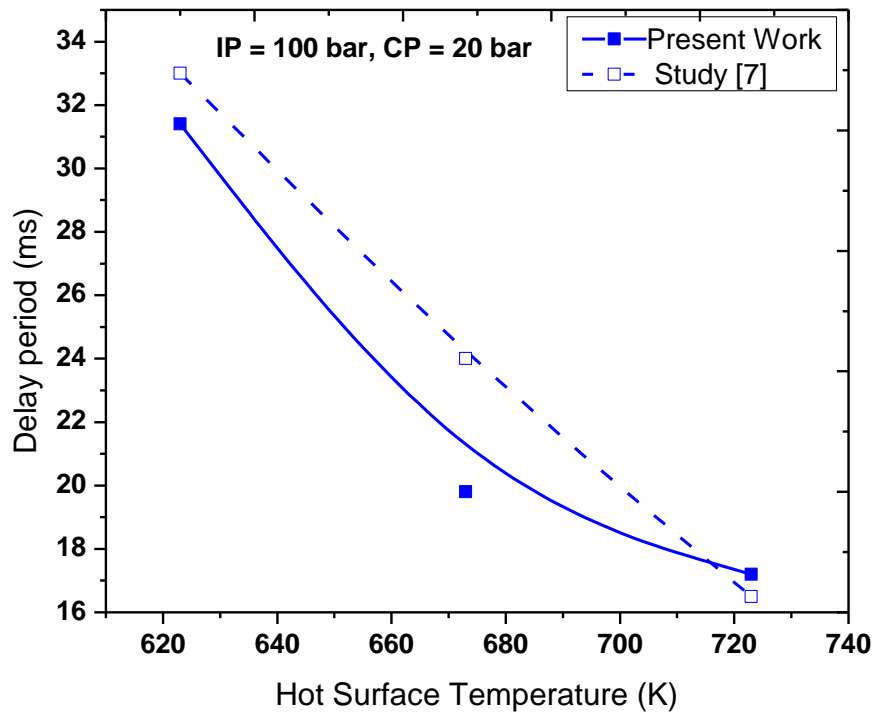

Figure 4.2 Delay period versus hot plate temperature 


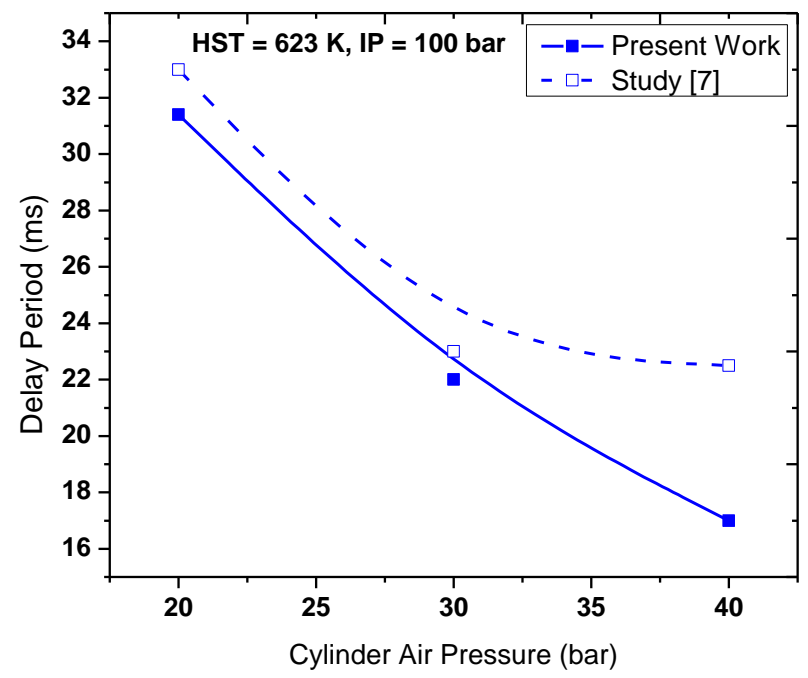

Figure 4.3 Variation of delay period with cylinder air pressure

Figures 4.1-4.3 show that results obtained in the present simulation study are in good agreement with the experimental studies carried out in CVCC [7]. The present simulated ignition delay period of impinging diesel duel sprays are found to be 10-15\% less in magnitude as compared to experimental results at same operating conditions. Therefore, results obtained in the present simulation work are validated quite well by the experimental work [7].

\section{Conclusions}

In the present work, simulations were carried out to quantify the effects of fuel injection pressure, hot plate temperature and cylinder air pressure on important combustion characteristics like ignition delay/delay period of impinging diesel fuel sprays in a constant volume combustion chamber. The numerical methodology was developed with an aim to control ignition characteristics for better combustion. Ignition delay period was calculated with the help of static temperature versus time plot. It was found that ignition delay period decreases with an increase in fuel injection pressure, increase in cylinder air pressure and increase in hot plate temperature, keeping the other two parameters fixed. The simulated results obtained in the present study showed the same trend and are in fairly good agreement with experimental results for the same operating conditions.

\section{Conflict of Interest}

The authors declare no conflict of interest.

\section{References}

[1] J.B. Heywood., Internal Combustion Engines Fundamentals, Second Ed., McGraw Hill International, New York, 2011.

[2] A.R. Semin, R.A. Bakar., Comparative performance of direct injection diesel engines fueled using compressed natural gas and diesel fuel based on GT- POWER simulation, Am. J. Appl. Sci. Vol 5, Issue 5, pp.540-547, 2008. 
[3] Stone, R., Introduction to internal combustion engines (4th ed.), Hampshire: Palgrave MacMillan, 2012.

[4] Ladommatos, N., Xiao, Z., \& Zhao, H., The effect of piston bowl temperatures on diesel exhaust emissions. Proceedings of the Institution of Mechanical Engineers, Part D: Journal of Automobile Engineering, 219, 371-388, 2005.

[5] Rehman, S. and Zaidi, K., Study of Ignition Delay of Certain Blended Petroleum Fuel Sprays in a Cylindrical Combustion Chamber, An International Journal of Science and Technology (S \& T Review), ISSN: 2231-5160, Vol-1, No-2, pp-65-76, 2012.

[6] Rehman, S., Sensor based measurement techniques of fuel injection and ignition characteristics of diesel sprays in DI combustion system, Alexandria Engineering Journal, 55, 2391-2403, 2016 [7] Rehman, S., Hot Surface Ignition and Combustion Characteristics of Sprays in Constant Volume Combustion Chamber Using Various Sensors, Cogent Engineering, ISSN: 2331-1916, (Taylor and Francis Publication), 2018.

[8] Rehman, S., Alam, S. S., Combustion and Soot Formation Characteristics of Homogeneous Supercritical Sprays of Dieseline Blend in Constant Volume Chamber, AIMS Energy, 8(5): 959987, 2020.

[9] Rehman, S., Alam, S. S., "Rate of Heat Release Characteristics of Supercritical Sprays of Dieseline Blend in Constant Volume Combustion Chamber" Results in Engineering-2020,100121, 2020 .

[10] Guerrassi, N., \& Champoussin, J. C., Experimental study and modeling of diesel spray/wall impingement (SAE paper 960864), 1996.

[11] Chown, D., Habbaky, C., \& Wallace, J. S., An experimental investigation of combustion chamber design parameters for hot surface ignition. In ASME. Internal Combustion Engine Division Fall Technical Conference, Volume 1: Large Bore Engines; Fuels; Advanced Combustion; Emissions Control Systems, V001T03A018, 2014.

[12] Khalid, A., Yatsufusa, T., Miyamoto, T., Kawakami, J., \& Kidoguchi, Y., Analysis of relation between mixture formation during ignition delay period and burning process in diesel combustion (SAE Paper 2009-32-0018). pp. 1-10, 2009.

[13] Lapuerta, M., Sanz-Argent, J., \& Raine, R. R., Ignition characteristics of diesel fuel in a constant volume bomb under diesel-like conditions. Effect of the operation parameters. Energy \& Fuels, 28, 5445-5454, 2014.

[14] Ganesan, V., Internal combustion engines. 4th Ed, 2012. 